\title{
Planejamento Urbano e Ambiental no Canal das Pedrinhas-Ap (Brasil): entraves e desafios
}

Urban and Environmental planning in Canal das Pedrinhas -AP (Brazil): barriers and challenges

Planificación urbana y ambiental en el Canal das Pedrinhas-AP (Brasil): obstáculos y desafios

\section{Josiane Pereira Cardoso}

Mestranda em Desenvolvimento Regional, UNIFAP, Macapá, Brasil rita.josi@hotmail.com

Netiê Isabel da Silva Oliveira Mestranda em Desenvolvimento Regional, UNIFAP, Macapá, Brasil netieoliveira@gmail.com

José Francisco de Carvalho Ferreira Doutor em Geografia e Planeamento Territorial, Pós-doutorando em Desenvolvimento Regional, UNIFAP, Brasil zfcofer@gmail.com 


\section{RESUMO:}

O Plano Diretor é um dos elementos, que elaborado e aplicado de forma adequada, auxilia no desenvolvimento de estados, cidades ou bairros de maneira ordenada e que, devidamente de acordo com a legislação ambiental, proporciona qualidade de vida e melhora a sustentabilidade da cidade. Nessa premissa, buscou-se compreender como ocorreu a ocupação do bairro das Pedrinhas e qual o impacto ambiental/social causado pela utilização de seu canal como indicador do desenvolvimento local e, ao mesmo tempo, principal meio para o comércio ilegal de madeiras. O período escolhido para estudo compreende os anos de 1990 a 2010, momento pelo qual o bairro apontou maior dinâmica no seu crescimento. O método utilizado foi o Dialético e as técnicas foram análise documental, levantamento bibliográfico e entrevistas indiretas. Percebeu-se que a ocupação desordenada trouxe sérios problemas ambientais e que o comércio ilegal no canal é um relevante promotor do desenvolvimento local.

PALAVRAS-CHAVE: Planejamento Urbano. Planejamento Ambiental. Canal das Pedrinhas.

\section{ABSTRACT:}

The Directive Plan is one of the elements that, drawn up and implemented appropriately, assists in developing states, cities or neighborhoods in an orderly manner and, in accordance with environmental legislation, provides quality of life and improves sustainability of the city. Thus, we sought to understand how occurred the occupation in the neighborhood of Pedrinhas and which environmental/social impact caused by the use of it channel as indicator of local development and, at the same time, the primary means for illegal trade of wood. The period chosen for study comprehends the years 1990 to 2010, in which time the district made more dynamic in its growth. The method used was the dialectic and the techniques were documental analysis, literature and indirect interviews. It was observed that the disorderly occupation brought serious environmental problems and the channel, and the illegal trade of wood in the channel is a relevant local development promoter.

KEYWORDS: Urban Planning. Environmental Planning. Canal das Pedrinhas.

\section{RESUMEN}

El Plan Maestro es uno de los elementos que, desarrollado y aplicado adecuadamente, ayuda en el desarrollo de los estados, ciudades o barrios de una manera ordenada y que, de acuerdo con la legislación ambiental, proporciona calidad de vida y aumenta la sostenibilidad de la ciudad. En esta premisa, hemos tratado de entender cómo se produjo la ocupación en el barrio de Pedrinhas y cual el impacto ambiental / social causado por el uso de su canal como indicador de desarrollo local y, al mismo tiempo, el medio principal para el comercio de madera ilegal. El período elegido para el estudio abarca los años 1990 a 2010, momento en el cual el distrito se hizo más dinámico en su crecimiento. El método utilizado fue el dialéctico y las técnicas fueran análisis documental, de la literatura y entrevistas indirectas. Se observó que la ocupación desordenada trajo graves problemas ambientales y que el comercio ilegal en el canal es un importante promotor del desarrollo local.

PALABRAS-CLAVE: Planificación urbana. Planificación Ambiental. Canal das Pedrinhas. 


\section{INTRODUÇÃO}

O planejamento, hoje, sem dúvida, é essencial para se pensar em uma ocupação de forma ordenada e assegurar às pessoas um espaço que proporcione qualidade de vida e a sustentabilidade da cidade. Na obra Planejamento Urbano e Meio Ambiente, Cassilha \& Cassilha (2009) apontam para a dinâmica no crescimento das cidades, pois, à medida que a malha urbana cresce desordenadamente, necessita-se de investimento em infraestrutura. Outro ponto relevante nessa dinâmica é a elaboração e aplicação do Plano Diretor evidenciada por Tostes (2006).

Analisando os movimentos espaciais decorrentes das ocupações humanas, percebem-se as grandes transformações que ocorrem durantes esse processo, que, muitas vezes, se dá de forma ilegal e traz grandes danos ao meio ambiente, ocasionando um ambiente inóspito e sem infraestrutura para a permanência de pessoas.

Compreender como acontecem as dinâmicas de ocupações indevidas nos espaços urbanos e de que forma a ilegalidade está atrelada dentro desse contexto é fundamental para a concepção de como é o processo de construção e transformação do mesmo. Sob essa ótica, analisar como ocorreu o processo de ocupação da área que envolve o canal das Pedrinhas e como o comércio ilegal de madeira está inserido neste local, permite a contextualização e compreensão das dinâmicas sociais, econômicas e ambientais existentes no referido bairro.

O bairro das Pedrinhas, assim como os demais bairros de Macapá, tem suas peculiaridades. Uma de suas características é o crescimento populacional intenso, em consequência da migração de pessoas de outros estados, após a transformação do então Território Federal em Estado do Amapá (1988) e a criação da Zona de Livre Comércio de Macapá e Santana (1991). Em uma ocupação sem planejamento percebem-se vários problemas de ordem social, com práticas excludentes e discriminatórias por parte do poder público. Percebe-se também que as questões ambientais são deixadas à parte, ocasionando danos irreparáveis ao meio ambiente.

Nesse prisma, surgem algumas inquietações, as quais se referem, principalmente, às consequências ocasionadas pela apropriação indevida no referido local e o comércio ilegal de madeira, realizado no canal das Pedrinhas, o qual implica diretamente na economia local.

O canal das Pedrinhas tem uma grande relevância, pois interfere na dinâmica e economia local. É considerado, por sua comercialização madeireira, um dos principais pontos comerciais da cidade de Macapá e também é caracterizado pelo seu intenso fluxo migratório, juntamente com o Porto de Santana, do Igarapé da Fortaleza, do Igarapé das Mulheres e do Canal do Jandiá.

Com esta pesquisa almeja-se compreender a dinâmica existente no canal das Pedrinhas e suas interferências locais, sua epistemologia que ocorreu de maneira desordenada e qual o impacto ambiental/social/econômico causado pela utilização deste como principal meio para o comércio informal de madeira. Averiguar as políticas adotadas pelos órgãos competentes para a regularização do comércio na área e a melhora na qualidade de vida de seus agentes sociais é outro ponto relevante durante a realização da mesma. 
O método utilizado foi o Dialético acompanhado de uma pesquisa exploratória. As técnicas adotadas foram levantamento bibliográfico, análise documental, visitas in loco e entrevistas informais com moradores e em órgãos públicos (SEMA, IBAMA, SEMOB e SEMDUH), responsáveis pela fiscalização e implantação de políticas de infraestrutura, econômicas e sociais, com uma estratégia baseada nos aspectos empíricos e qualitativos.

$\mathrm{O}$ artigo está dividido em duas fases. Na primeira, será feita uma abordagem sobre planejamento urbano e ambiental, na qual também será incluída uma breve discussão sobre a importação da elaboração e implantação do Plano Diretor. Na segunda, será tradado o objeto de estudo, o Canal das Pedrinhas, com enfoque voltado para a realidade e a atuação do poder público no referido local. Por fim, serão expostas as considerações finais.

\section{PLANEJAMENTO URBANO E AMBIENTAL}

Modificadas e em constante crescimento, as cidades vão mudando através de ações cotidianas das pessoas, que se apropriam e intervêm no espaço de diferentes formas. A partir dessas intervenções, sem que sejam tomadas as devidas providências, começam a surgir diversos problemas (CASSILHA \& CASSILHA, 2009).

Percebe-se, então, para organização e apropriação legal do espaço, a necessidade de implementar ações advindas do Poder Público. Nota-se, no Brasil, que o planejamento e regulação urbanística têm pouco comprometimento com a realidade concreta e reproduz e reafirma desigualdades e privilégios nas cidades. Porém, para a cidade ilegal não há planos, nem ordem (MARICATO, 2002).

O planejamento e a gestão, utilizados pelo legislador, deveriam configurar instrumentos jurídicos e políticos de uma sociedade democrática e participativa, para solucionar os problemas urbanos identificados e oriundos das transformações que se configuram em uma cidade, em ordem à sua sustentabilidade. O planejamento e a gestão nada mais são que estratégias de desenvolvimento urbano, alimentadas por pesquisa social básica, tanto teórica, quanto empírica, e seus principais objetivos derivam principalmente da melhoria da qualidade de vida e do aumento da justiça social (SOUZA, 2011).

No Brasil, em especial, um dos seus grandes problemas é a falta de planejamento ou um planejamento inadequado. Em uma visão mais capitalista, o planejamento urbano é um instrumento do Estado que serve a reprodução do status quo (ALVES e VALE, 2014). Percebese que os problemas e conflitos urbanos, presentes nas transformações das cidades, não são resolvidos por falta de competências técnicas, pois o planejamento serve para prever o progresso de um problema, conhecer os desdobramentos de um processo para se precaver de futuros problemas. Para Souza (2011), planejamento é a preparação para a gestão futura, buscando-se evitar ou minimizar problemas e ampliar margens de manobra.

A gestão urbana, a partir do planejamento, deve garantir o funcionamento de uma cidade nos seus quatro principais aspectos: habitação, trabalho, lazer e circulação. Nessa premissa, deve se revelar de um conjunto de instrumentos, principalmente a legislação urbanística básica de uso e ocupação do solo, atividades e tarefas que visem assegurar o adequado funcionamento da cidade (CASSILHA \& CASSILHA, 2009). A implementação da gestão ambiental urbana de 
posse de seus instrumentos é uma possibilidade para o município de procedimento de intervenção e prevenção atuando continuamente em planejamento (ALVES e VALE, 2014).

No planejamento deve-se levar em conta que o Homem, durante o processo de urbanização, interfere no ambiente para sua melhor comodidade. É fato que algumas dessas interferências estão ocorrendo de maneira desordenada e, facilmente, esquece que o meio natural é finito e frágil. Como exemplo, podemos citar os desmatamentos, as modificações nos diversos ecossistemas, a impermeabilização e a erosão do solo, a poluição e posterior canalização dos rios, tendo como consequências as diversas catástrofes naturais ocorridas atualmente e as alterações climáticas num nível global (CASSILHA \& CASSILHA, 2009).

Percebe-se que a cidade, em seu crescimento e desenvolvimento, depara-se com seus conflitos e desafios, e o Planejamento Urbano, sem o Planejamento Ambiental, não responde, mediante o quadro atual, às necessidades sociais que vão além dos projetos urbanos e restrições legais. Nesse sentido, Silva e Werle (2007, p.11) apontam que,

[...] o Planejamento Ambiental torna-se de extrema importância para a constituição sustentável social e espacial de uma sociedade; porém a forma de legislação associada a um processo eficaz de execução e fiscalização dos mecanismos legais existentes talvez seja o grande dilema para a viabilização de projetos sustentáveis, sem esquecer de que a conscientização social e ambiental é indissociável desse processo. A gestão ambiental no território deve ocorrer a partir dos municípios [...], envolvendo a participação das instituições públicas, comunidades locais e setores econômicos na implementação de projetos e ações no espaço urbano e regional.

No entanto, no Brasil foi somente a partir da década de 80 que se iniciou, de fato, a política ambiental (SILVA e WERLE, 2007). Foi com a constituição de 1988 e com a implementação de Constituições Estaduais, que se criou uma instrumentação eficaz, delegando responsabilidades aos estados e definia a gestão ambiental no contexto regional. O processo de descentralização, da federação para os estados, se deu na década de 90, período pelo qual a maioria dos estados criaram secretarias e proporcionaram qualificação profissional, o monitoramento e fiscalização do território.

De acordo com Silva e Werle (2007, p.11),

[...] percebeu-se que a exploração descontrolada da natureza e o estabelecimento de um estado crítico quanto aos problemas ambientais ocorre a partir das cidades, ou seja, dos municípios... O processo de democratização brasileira, de crescimento econômico e demográfico associado à municipalização nos estados direcionou para um processo de gestão ambiental no sentido dos municípios, associado às políticas moderadas de melhoria de infraestrutura, saúde e educação. Entretanto, a descentralização da gestão ambiental para os municípios nem sempre está associada a um processo participativo e de conscientização ambiental dos diversos segmentos das sociedades locais, estes que também são os interessados na discussão e solução de problemas que atingem, diretamente, a qualidade de vida. 
É importante que a descentralização da gestão ambiental, em sua municipalidade e diversos seguimentos da sociedade, seja acompanhada da conscientização ambiental tanto dos agentes políticos, privados e sociais, para que estes possam orientar as ações, esclarecendo suas ferramentas e possibilidades à comunidade em geral.

A reestruturação administrativa e capacitação pessoal nos municípios devem ser pensadas como caminho eficiente na execução de atividades de licenciamento, monitoramento e fiscalização, sendo essencial para a implementação de uma política de gestão ambiental eficaz no contexto regional, estadual e nacional (ALVES e VALE, 2014).

\subsection{O Plano Diretor como instrumento de política urbana}

O Plano Diretor pode ser definido com um conjunto de preceitos e regras orientadoras dos diversos agentes que constroem e utilizam o espaço urbano. Ele faz parte da leitura da cidade real, envolvendo tanto questões relativas aos aspectos urbanos quanto aos aspectos sociais, econômicos e ambientais (CASSILHA \& CASSILHA, 2009). O Plano diretor tem como finalidade possibilitar a orientação e a atuação do poder público local e da iniciativa privada na ocupação e construção dos espaços urbanos, na oferta dos serviços públicos essenciais, visando assegurar melhores condições de vida para a população e com justiça social.

A aprovação no ano de 2001 do Estatuto da Cidade reforçou a necessidade da elaboração dos planos diretores, desta feita não mais como características técnicas, mas com participação de todos os setores sociais (TOSTES, 2006). Em consequência, em 2003, Macapá iniciou, com a participação de vários setores sociais, a elaboração do seu Plano Diretor Participativo, o qual foi aprovado em 2004. Convém salientar que várias medidas previstas para execução em um prazo de 01(um) ano não foram efetivadas em conformidade com o texto aprovado pela Câmara de Vereadores (TOSTES, 2006).

O Plano Diretor de Macapá contempla todos os instrumentos que proporcionem o desenvolvimento local com equidade social. No entanto, a realidade é totalmente diferente do que está disposto no estatuto, principalmente no que se refere à infraestrutura e meio ambiente, o que pode ser observado no seguinte artigo:

Art. 2ㅇ - São objetivos gerais do Plano Diretor de Desenvolvimento Urbano e Ambiental de Macapá:

1 - atender às necessidades de todos os habitantes quanto à qualidade de vida, à justiça social e ao desenvolvimento de forma sustentável.

Percebeu-se, em visita in loco, que tal objetivo não foi alcançado e que também não está sendo realizada nenhuma política relacionada a questões de infraestrutura que possa proporcionar qualidade de vida e justiça social.

Quanto à ocupação do território, sua ordenação deveria estar de acordo com os critérios estabelecidos no Plano Diretor: a) assegurar o acesso à habitação e aos serviços públicos; b) garantir o melhor aproveitamento da infraestrutura urbana; c) evitar a ocorrência de impactos ambientais negativos e riscos para a população e d) impedir a retenção 
especulativa dos imóveis urbanos. Contudo, não foi o que se percebeu durante a realização deste trabalho e em visita aos órgãos competentes. Notou-se que não há, no momento, nenhuma ação voltada para o Canal das Pedrinhas.

No entanto, na Legislação vigente sobre o bairro das Pedrinhas, percebe que, de acordo com o PDDUA 2004, ele está inserido no contexto hidroviário que seria acrescido de reestruturação e melhorias. De acordo com a Lei Complementar no 029/2004 - PMM que institui o Plano Diretor de Desenvolvimento Urbano e Ambiental de Macapá (PDDUA, 2004) sobre o Uso e Ocupação do Solo, o bairro das Pedrinhas está situado nas áreas de abrangência do Setor Residencial 2 (SR2). A Lei Complementar prevê para o SR2 o uso residencial uni e multifamiliar, atividades comerciais e de serviços de apoio à moradia.

O PDDUA (2004, p. 34), em seu Art. 63 indica "o Canal das Pedrinhas, regional, com potencial para ligação com as ilhas do rio Amazonas, com as localidades de Maruanum, Coração e Fazendinha.". Já no Art. 142 do PDDUA (2004), as margens do canal das Pedrinhas estão presentes como Área de Interesse para Reestruturação Urbana, com as seguintes diretrizes:

I - integração dos setores municipais responsáveis pelo meio ambiente e pela prestação de serviços urbanos; II - envolvimento de representantes da população local; III - ações conjuntas com o órgão estadual responsável pelo meio ambiente e com a concessionária de água e esgotos de Macapá; IV - inclusão de componentes referentes à: a) drenagem urbana; b) remoção de resíduos sólidos; c) geração de trabalho e renda;

d) educação ambiental.

Percebeu-se que, apesar da menção no PPDUA (2004) sobre a área das Pedrinhas como área de potencial regional e de interesse para reestruturação urbana, não foram encontrados registros de projetos que explorem este potencial descrito pelo plano, além do plano HJ Cole \& Associados (1976), que abrangeu parte da área das Pedrinhas - Avenida Equatorial, quando ainda nem era bairro oficial (PENAFORT, 2015).

\section{DINÂMICAS DO BAIRRO DAS PEDRINHAS NO CONTEXTO AMAPAENSE}

O Estado do Amapá, assim como os demais estados da região Amazônica, tem suas peculiaridades, características que o torna singular em relação aos demais estados. Localizado no extremo norte do país, ocupa uma área de $143.453 \mathrm{Km}^{2}$, correspondente a 1,6\% do Brasil e a 3,6\% da região norte. Faz fronteira com o Estado do Pará, Suriname e Guiana Francesa, e tem como capital a cidade de Macapá, e faz parte de dois grandes domínios geográficos: o amazônico e o oceânico, o que lhe atribui características muito particulares em termos de formação e estruturação de seus ambientes naturais, e faz dele um Estado constituído com grandes riquezas naturais.

O Estado é composto por 28 bairros oficiais e 32 não oficializados. Entre os oficiais está o bairro das Pedrinhas, onde fica localizado o canal das Pedrinhas, objeto de pesquisa (figura 1). 
Este bairro surgiu a partir de ocupações irregulares, durante a expansão urbana da Macapá. Está localizado na parte sudoeste da cidade e tem como características atividades comerciais desenvolvidas em seu canal que dá acesso ao rio Amazonas. O comércio se dá por embarcações que trazem produtos como madeira, açaí e peixe, e possui uma localização privilegiada por estar praticamente no centro da cidade, de frente para o rio Amazonas.

\section{Figura 1 - Localização do bairro das Pedrinhas no contexto nacional}

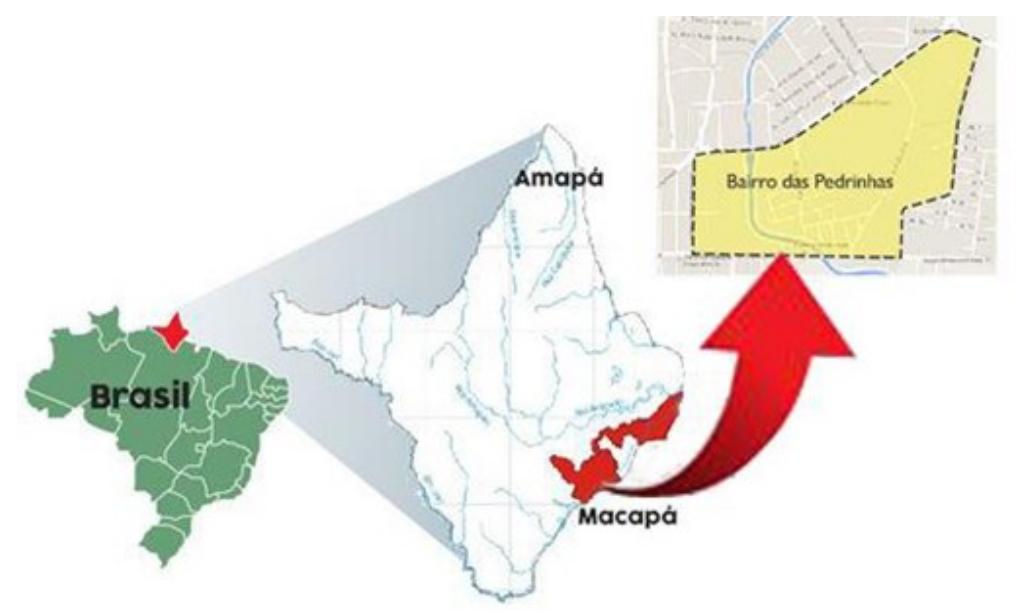

Fonte: PENAFORT, 2015

Apesar de características e localização distinta, é um bairro cheio de problemas relacionados à falta de infraestrutura, à ilegalidade do comércio madeireiro, à falta de aplicação da legislação ambiental vigente e à falta de fiscalização e intervenção por parte do poder público, que se exime de suas responsabilidades em relação às voltadas para a melhoria na qualidade de vida local.

\subsection{A OCUPAÇÃO DO CANAL DAS PEDRINHAS}

Classificado como uma área manancial, o canal das Pedrinhas (figura 2) é conhecido pelo fluxo de embarcações que trafegam comercialmente fazendo o transporte de madeiras e passageiros que entram e saem do estado sem o controle por parte dos órgãos competentes. $\mathrm{O}$ transporte de madeira, em sua maioria, surge a partir de um comércio ilegal, justamente pela falta de infraestrutura e fiscalização adequada por parte dos órgãos competentes. A degradação ambiental é, igualmente, uma característica do bairro, pois como foi ocupado sem o devido planejamento, trouxe grandes problemas relacionados a danos ambientais, principalmente, no que se refere a sua área de ressaca. 


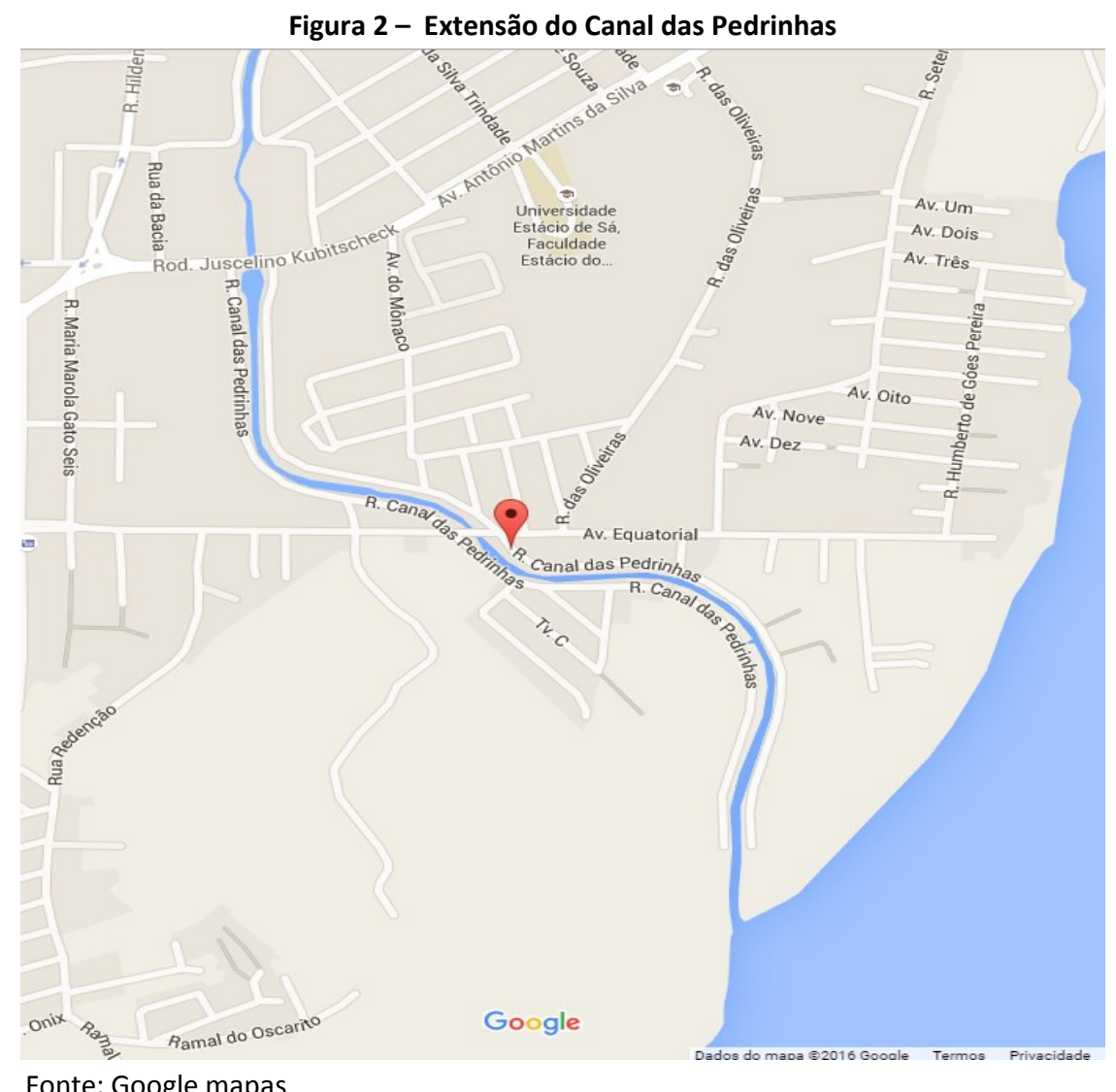

Fonte: Google mapas

Mesmo com todos os problemas, não se deve desconsiderar a importância dessa área no desenvolvimento socioeconômico na cidade de Macapá, pois é considerado um dos principais polos da economia local, curiosamente, pela atividade ilegal do comércio madeireiro.

Até metade da década de 80 , o referido canal tinha o título de igarapé, pois tinha como função serviços de drenagem e ainda estava em seu estado natural. No entanto, no período correspondente a 1983/1984, foi dado início a um processo de drenagem para o alargamento e aprofundamento do leito do igarapé, transformando-o em canal, mudando seu estado original para facilitar o fluxo de embarcações marítimas e a aceleração do processo de ocupação da área, restando somente resquícios das florestas de várzea e da vegetação litorânea na sua foz, diminuindo sua função ecológica (ROSÁRIO, 2001).

Foi após o processo de drenagem que começou um processo de ocupação desordenada por pessoas oriundas de outros estados, e se converteu em um polo econômico, com um importante agente relacionado ao fornecimento de matéria prima para a construção civil na cidade de Macapá.

Vale ressaltar que as transformações e os danos ambientais ocorridas neste local, devido a uma ocupação sem planejamento são perceptíveis, como os aterros, os alagamentos, poluição das águas e destruição da mata ciliar. O resultado dessa ocupação desordenada é um ambiente inóspito a seus moradores, com condições desfavoráveis pela falta de infraestrutura, com destaque para o saneamento básico, que expõe a população local a riscos de doenças. 
O intenso processo migratório ocorrido a partir da década de 50 ocasionou uma série de dificuldades para o então Território do Amapá (SOUZA, 2003), pois o grande número de migrantes era maior que a capacidade de geração de empregos, ocasionando um número considerável de desempregados, vivendo do comércio informal. Sem opção de moradias, começaram a surgir invasões em locais inóspitos, avançando sobre as baixadas alagadiças e adentrando nas áreas de ressaca. Este fenômeno se acentuou com a estadualização do Território Federal do Amapá (1998) e a criação da Zona de Livre Comércio de Macapá e Santana (1991) (PORTO, 2010).

Percebe-se que a ocupação espacial nativa da migração só se intensificou nesse período e, consequentemente, agravou alguns problemas de ordem social, econômica e ambiental no estado. O canal das Pedrinhas não se difere das demais condições estruturais de outros bairros, mas tem um agravante ambiental que, com o fluxo migratório e sem as políticas de urbanização, resultou na ocupação desordenada nas áreas de ressaca, ocasionando bolsões de pobreza nas áreas periféricas da cidade de Macapá. É notório que o bairro necessita da intervenção urgente do poder público, para que se inicie um processo de "desenvolvimento através de articulações das estruturas políticas, sociais e econômicas garantindo o bem-estar de sua população" (RODRIGUEZ, 2001, p. 2).

Uma curiosidade do bairro é que, apesar de todos seus problemas, o seu comércio formal e informal é bem desenvolvido, com uma grande circulação de capital, pessoas e mercadorias. É o setor madeireiro aquele que mais se destaca, com a premissa de que tais materiais são essenciais para a construção civil, induzindo o desenvolvimento dos outros segmentos comerciais no lugar.

$\mathrm{Na}$ verdade, esse desenvolvimento se deve à intensa concentração e trânsito de pessoas para as embarcações, o que demonstra que esse movimento é um fator determinante para a dinâmica de ocupação e fluxo comercial que se concretiza no local. No entanto, por falta de políticas eficazes voltadas para o referido local e diante de uma observação sistemática, percebe-se que os moradores e trabalhadores não usufruem do desenvolvimento social e sofrem com a falta de assistência do Poder Público (PORTO, 2000).

É fato que o Poder Público, tanto na esfera Estadual quanto Municipal, precisam dar alternativas à população local, pensar em opções para que o capital gerado no bairro possa circular no mesmo e proporcionar o desenvolvimento local com um padrão econômico e social mais igualitário.

\subsection{O COMÉRCIO MADEIREIRO - CARACTERÍSTICA MARCANTE DO CANAL DAS PEDRINHAS}

Na Amazônia, no que diz respeito à exploração madeireira, pode dizer-se que é uma prática existente há mais de trezentos anos, associada, restritamente às florestas de várzeas (Barros e Veríssimo, 2000). No entanto, com a abertura de estradas no referido local, surge uma nova dinâmica para essa ação, que tem com alvo, de maneira cada vez mais crescente, as florestas de terra firme.

No início, os impactos causados não eram tão grandes, pois os exploradores tinham o objetivo de suprir somente o mercado local. Mas, com a destruição da Mata Atlântica, principal fonte 
de matéria-prima para o país, percebe-se que houve um aumento significativo na degradação de florestas nativas na Amazônia nas últimas décadas. Este fato ocasionou e tem ocasionado sérios danos ambientais, já que a Amazônia se tornou fonte de madeira para o mercado nacional e internacional (FERREIRA, RANGEL e DAMASCENO, 2009, p.11).

A irregularidade comercial de madeira no canal das pedrinhas é tão notória quanto as dificuldades de combatê-la, pois a ilegalidade se dá, principalmente, pelo processo de extração das toras que é ilegítimo e devastador no que desrespeito à legislação ambiental. Com isso, surge a clandestinidade pela falta de fiscalização por parte dos órgãos responsáveis, que se abstêm da problemática, alegando a fomentação ao "desenvolvimento local" por parte dessa relação comercial.

Alguns órgãos fiscalizadores como o IBAMA, por exemplo, entendem que se acirrar a fiscalização poderá causar conflitos sociais e as mazelas locais tenderão a aumentar. Outro ponto apontado é que, com a fiscalização nas estâncias e madeireiras, localizadas no entorno do canal das Pedrinhas, tais extrativistas poderiam procurar outros mercados, o que, de certa forma, não eliminaria o problema e sim o deslocaria para outro ponto, ocasionando o aumento nos problemas sociais existentes no local.

Diante do exposto, percebe-se a importância de criar políticas que favoreçam a legalidade do ciclo madeireiro, desde o corte da tora, beneficiamento a sua comercialização. Mas para que isso seja possível, são necessários três elementos: o título de posse, o plano de manejo e o DOF, pois sem esse tripé a comercialização da madeira continua sendo caracterizada como ilegal.

Outro ponto que chamou a atenção foi a impotente e frágil atuação do IBAMA, o qual alega temer, com suas fiscalizações rigorosas, um impacto social que seria desastroso para aquela comunidade, pois acarretaria no fechamento de madeireiras, que, de forma semi-exploratória, têm uma relação de trabalho com extratores (ribeirinhos), barqueiros (que transportam e vendem o produto) e os donos de estâncias, o que iria fragilizar a circulação de renda e o desenvolvimento local. Nesse viés, percebe-se que os ribeirinhos, que são a parte mais fraca nessa relação comercial, veem nessa atividade, mesmo exploratória, a única possibilidade de obtenção de renda e sem esta teriam que procurar outra atividade, o que poderia desencadear sérios problemas sociais, como a migração desordenada para áreas urbanas ocasionando o inchaço populacional com sérias mazelas.

\subsection{POLÍTICAS PÚBLICAS NAS PEDRINHAS: ÓRGÃOS E DEVIDAS COMPETÊNCIAS}

Entender a necessidade e a importância do planejamento é essencial para que se possa dimensionar a possibilidade de êxito de uma gestão municipal na elaboração e execução de políticas públicas para determinado local.

Nesse sentido, percebe-se a urgência de elaboração e implantação de políticas no bairro das Pedrinhas, sobre tudo em seu canal, que tem uma importância significativa na dinâmica local. No entanto, em visita a algumas secretarias como a SEMA, a SEMOB e a SEMDUH, não foi encontrado nenhum registro de planejamento para a criação do bairro das Pedrinhas e nem para um intervenção relacionada aos problemas atuais do referido bairro. Com isso conclui-se 
que a origem do mesmo se deu de forma desordenada, o que ocasionou sérios problemas relacionados à falta de infraestrutura e de ordem social e econômica que hoje são difíceis de resolver.

Quanto à infraestrutura, o bairro teve duas obras de destaque, a drenagem do canal (que viabiliza a navegação de barcos que fazem o transporte de pessoas e matérias-primas, movimentando o capital local) e a construção da ponte sobre o canal, a qual facilitou na locomoção das pessoas e a rotação do transporte público no local.

No que desrespeito à saúde, a população sofre pela falta do saneamento básico e com a poluição existente no canal, o que ocasiona doenças endêmicas. A poluição no canal só tende a aumentar já que muitos resíduos oriundos da madeira são jogados no local, juntamente com os dejetos sanitários e muitas vezes o lixo diário (figuras 3 e 4).

Figuras 3 e 4 - acúmulo de lixo que podem ocasionar sérios problemas relacionados à saúde.
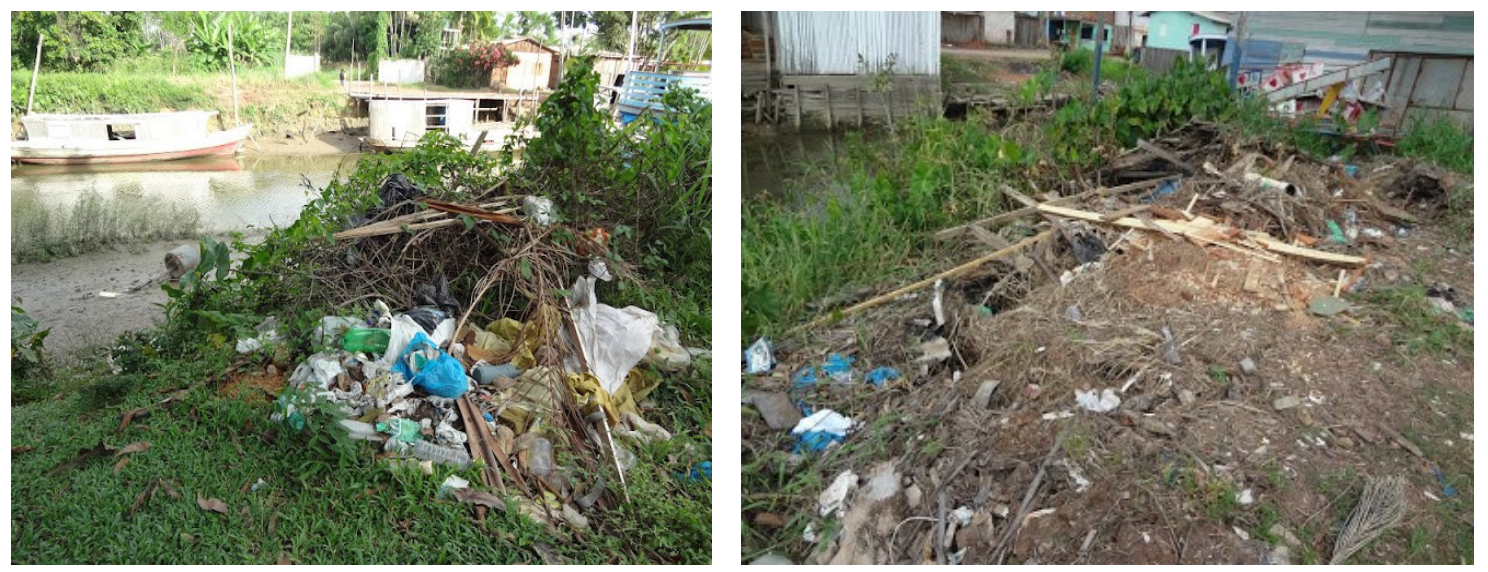

Percebe-se que os problemas em torno do bairro são muitos, como a deficiência de políticas públicas na saúde, na educação, na ineficácia da segurança pública, no aumento da prostituição e o tráfego de drogas. São problemas que precisam ser amenizados para o bem da população local. No entanto, para que isso aconteça, faz-se necessário a intervenção do poder público com alternativas que possibilitem a melhora na qualidade de vida e a sustentabilidade local.

As soluções podem e devem ser advindas do poder público, mas com participação da comunidade, pois entende-se que a junção das duas forças é que fará a transformação do referido bairro. No que tange aos problemas e possíveis soluções, algumas sugestões apontadas por Penafort (2015) estão assinaladas no quadro 1. 
Quadro 1 - Quadro de problema e possíveis soluções para o bairro das Pedrinhas

\begin{tabular}{|l|l|}
\hline \multicolumn{1}{|c|}{ PROBLEMAS } & \multicolumn{1}{|c|}{ POSSÍvEIS SOLUÇõES } \\
\hline $\begin{array}{l}\text { Vias: As vias do trecho do canal das Pedrinhas são } \\
\text { estreitas para comportar o fluxo em duplo sentido. }\end{array}$ & $\begin{array}{l}\text { Unificar o sentido das vias, uma delas seria no sentido } \\
\text { Rod. JK - Av. Equatorial, e a outra no sentido inverso. }\end{array}$ \\
\hline $\begin{array}{l}\text { Aglomeração de casas: As casas locadas no trecho do } \\
\text { canal não possuem afastamento necessário que } \\
\text { possibilite a geração de conforto térmico, e interfere } \\
\text { na qualidade de vida dos moradores. }\end{array}$ & $\begin{array}{l}\text { Diminuir a quantidade de habitações, reordenando-as } \\
\text { com os afastamentos necessários para a obtenção de } \\
\text { conforto térmico. E relocar para conjuntos } \\
\text { habitacionais do governo os moradores que já } \\
\text { demonstram interesse em sair da área e não o fazem } \\
\text { por falta de condições financeira. }\end{array}$ \\
\hline $\begin{array}{l}\text { Madeireiras: As madeireiras não possuem um } \\
\text { ordenamento planejado. }\end{array}$ & Indicação de um mercado madeireiro \\
\hline $\begin{array}{l}\text { Despejo de dejetos: não há qualquer tratamento de } \\
\text { esgoto no despejo de dejetos no canal }\end{array}$ & Propor um sistema de esgoto ecológico para a área. \\
\hline $\begin{array}{l}\text { Falta de área portuária de pequeno porte: a falta de } \\
\text { um lugar para ancorar as pequenas embarcações gera } \\
\text { um aglomerado de barcos no canal navegável. }\end{array}$ & $\begin{array}{l}\text { Propor um deck, para embarcações de pequeno porte } \\
\text { ancorarem. }\end{array}$ \\
\hline $\begin{array}{l}\text { Insegurança: Não há qualquer tipo de guarita que } \\
\text { fiscalize a entrada e saída de embarcações, } \\
\text { possibilitando o transporte de substâncias ilegais, como } \\
\text { drogas ilícitas, por exemplo. }\end{array}$ & $\begin{array}{l}\text { Propor iluminação, acessibilidade urbana, mobiliários } \\
\text { urbanos, a fim de que o acesso à urbes contribua de } \\
\text { forma positiva deixando o lugar mais seguro. }\end{array}$ \\
\hline
\end{tabular}

Fonte: Adaptado de PENAFORT, 2015, p. 43.

As dificuldades são muitas, mas com a intervenção do poder público e colaboração da população local, principalmente no que se refere ao tratamento com lixo doméstico, que causa problemas à saúde, conta-se que os problemas serão amenizados. Outro ponto relevante abordado por Penafort (2005) é uma proposta de intervenção urbana para o espaço onde está localizado o canal das Pedrinhas. As ruas do bairro, de mão dupla, dificultam o trânsito local, por serem estreitas. No entanto, isso poderia ser resolvido com uma mudança para via de mão única entorno do canal, o que facilitaria a locomoção das pessoas e a circulação dos automóveis, tornando o espaço mais acessível e com menos risco para o surgimento de acidentes.

\section{CONSIDERAÇÕES FINAIS}

Durante a realização desta pesquisa observou-se algumas peculiaridades que não são decorrentes só do cenário local e sim das mazelas que assolam o povo brasileiro e, diga-se de passagem, têm maiores impactos nas áreas periféricas, por estas não serem planejadas nem terem infraestrutura, cansando sérios problemas e danos irreparáveis ao meio ambiente.

Os danos ambientais são muitos, mas poderiam ser amenizados com atitudes simples tanto da sociedade civil como do Poder Público. Poderia se começar pela coleta de lixo, tanto por parte do município quanto da comunidade envolvida. Também seria possível campanha ambiental em parceria com órgãos ambientais e a associação de bairro, escolas e igrejas.

Contatou-se também a ilegalidade do comércio madeireiro no canal das Pedrinhas, mas percebeu-se que além de atividade econômica, esse processo está arraigado à cultura amazônida, já que a atividade extrativista é essencial aos "caboclos da floresta" como característica da sua própria existência. 
Nesse sentido, deve se encontrar uma solução adequada, no intuito de que os órgãos reguladores possam proporcionar a legalidade das terras e, consequentemente, as fiscalizações possam ocorrer com o intuito de colaborar no crescimento de tal atividade e evitar o surgimento do comércio clandestino, promovendo a sustentabilidade local.

Percebe-se que o canal das Pedrinhas está longe de ser agraciado com melhorias provenientes do Poder Público, o que não proporciona um desenvolvimento com melhoras sociais e uma divisão de renda mais justa. No entanto, destaca-se o potencial papel da sociedade civil, uma vez que, se organizada, poderia cobrar das esferas municipais, estaduais e federais possíveis soluções para os problemas encontrados no local.

Vale ressaltar que, mesmo com todos os problemas perceptivos, o bairro possui uma localização privilegiada, com características que lhe são peculiares. Tem uma população de origem bem diversificada, com as mais diversas culturas, o que enriquece a história local. É possível acontecer a mudança, contudo, acredita-se que para que isso aconteça, seja necessário o bom senso das autoridades, a união e conscientização da comunidade local e a promoção de ações que promovam a sustentabilidade local.

\section{REFERÊNCIAS BIBLIOGRÁFICAS}

ALVES, Cledson; VALE, Jones Remo Barbosa. O planejamento e a gestão ambiental no município de Belém/PA: concepções e ações do poder público local. VII Congresso brasileiro dos Geógrafos. Vitória, 2014.

BARROS, Ana Cristina; VERÍSSIMO, Adalberto (Eds). A expansão madeireira na Amazônia: impactos e perspectivas para o desenvolvimento no Pará. 2o ed. Belém: Imazon, 2002.

CASSILHA, G. CASSILHA, S. Planejamento Urbano e Meio Ambiente. Curitiba: IESDE BRASIL S.A. 2009.

CASTELO, Rogério. Bairros de Macapá: Pedrinhas (Parte 2 - O Canal das Pedrinhas). Disponível em <http://casteloroger.blogspot.com.br> Acesso em 02 ago. 2014.

FERREIRA, M. A.; RANGEL, S. C.; DAMASCENO, W.S. Desenvolvimento sustentável e a comercialização clandestina de madeira no canal das Pedrinhas. Monografia apresentada à banca examinadora da Universidade Federal do Amapá - UNIFAP, 2009.

PENAFORT, Laís Alves. 0 modo de viver ribeirinho na espacialidade do bairro das pedrinhas: Uma Proposta de Revitalização para o Canal das Pedrinhas. TCC (Arquitetura e Urbanismo), da Universidade Federal do Amapá UNIFAP, Macapá, 2015.

MARICATO, Ermínia. Brasil: cidades em crise. São Paulo, 2003. Vozes.

PREFEITURA MUNICIPAL DE MACAPAÁ - PMM. Plano diretor de desenvolvimento urbano e ambiental de Macapá. Macapá, 2004.

PORTO, Jadson L. R. Amapá: Principais transformações econômicas e institucionais -1943-2000. 2a Edição. Macapá, 2000.

RODRIGUEZ, J. M. M. Desenvolvimento sustentável: níveis conceituais e modelos. In RODRIGUEZ, J. M. M. \& SILVA, E. V. da. Desenvolvimento local sustentável. Fortaleza: Universidade Federal do Ceará, 2001.

ROSÁRIO, Ubiratan. Breves a capital das ilhas: um estudo de cultura local no Marajó. Breves - PA: Universidade Federal do Pará (Campus Universitário de breves), 2001.

SOUSA, Milton. Amazônia: história, desenvolvimento e geografia. São Paulo: EDUSP, 2003. 
SILVA, G. J. A.; WERLE, H. J. S. Planejamento urbano e ambiental nas: da Cidade à sustentabilidade, da lei à realidade. PAISAGENS EM DEBATE revista eletrônica da área Paisagem e Ambiente, FAU. USP - n. 05, dezembro 2007

SOUZA. Marcelo Lopes de. Mudar a Cidade: Uma Introdução Critica ao Planejamento e à Gestão Urbanos. 3a ed. Rio de Janeiro. Bertrand Brasil, 2011.

TOSTES, José A. Planos Diretores no Estado do Amapá - Uma Contribuição para o Desenvolvimento Regional. Macapá: J. A. Tostes, 2006. 